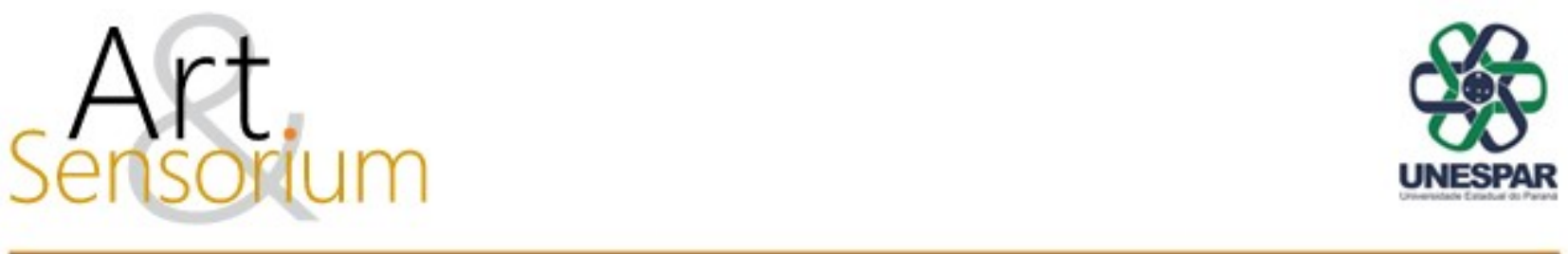

\title{
BELLMER, HANS. TEXTOS DE HANS BELLMER. TRADUÇÃO DE ALEXANDRE RODRIGUES DA COSTA
}

DOI: https://doi.org/10.33871/23580437.2021.8.2.285-289

Lucas Henrique da Silva ${ }^{1}$

Resenha de: COSTA, Alexandre Rodrigues da (org.). Corpos labirínticos: textos de Hans Bellmer. Tradução de Alexandre Rodrigues da Costa. Rio de Janeiro: Gramma, 2019.

Hans Bellmer nasceu em 1902, na cidade de Katowice (Silésia), na época parte do Império Alemão. Aos 20 anos, Bellmer fez a sua primeira viagem à Paris, onde passaria a sua vida depois de deixar Berlim de vez em 1938. Bellmer deixou a mãe, esposa, filhas; uma prima por quem nutria uma obsessão e uma troca intelectual, mas levou a Boneca para Paris. A Alemanha era um passado na vida artística de Bellmer, só seria relembrada em textos críticos. Entretanto, Berlim é cenário do encontro ao acaso entre Bellmer e sua companheira de vida e arte, Unica Zürn. A interessante colaboração de Bellmer e Zürn no contexto do movimento surrealista é analisada no trabalho de Renee Riese Hubert intitulado Magnifying mirrors (1994). É conhecida as fotografias do corpo de Unica amarrado por cabos de aço, a simular amputações e proliferações, assinadas por Bellmer para a capa da edição de 1958 da principal revista surrealista, Le surréalisme, même. O prefácio de Bellmer ao trabalho de Zürn, Oracles et Spetacles (1967), encontra-se pela primeira vez em português no livro de Alexandre da Costa, Corpos labirínticos. Os textos traduzidos por Alexandre da Costa exibem o desafiador pensamento do autor de "Pequena anatomia da imagem".

O espírito questionador de Bellmer fez com que ele estivesse sempre em oposição com as figuras castradoras, a começar pelo seu pai, que ganharia a aversão completa do filho ao se filiar ao partido nazista alemão. Bellmer opôs-se cedo ao rumo da política fascista, o que fez com que tomasse uma posição: dedicar-se exclusivamente à arte, ou melhor, às atividades "inúteis", pois recusava a utilidade fascista que enxergava o corpo como um objeto com manual de instruções. Por pressão paterna, Bellmer já havia estudado engenharia e design. Esse conhecimento, ele transferiu para a criação de um objeto que conhecemos como A Boneca (Die Puppe), legendária escultura de 1934, produzida em gesso e fibra, repleta de mecanismos e possibilidades óticas e anatômicas. O livro foi publicado com o dinheiro do próprio autor, continha dez fotos do objeto em poses insinuantes, montada e desmontada, no cenário do porão da casa de Bellmer, a dividir espaço com fantasias de

\footnotetext{
${ }^{1}$ Doutorando em Estudos Literários pela UNESP - Campus de Araraquara, São Paulo, Brasil. Bolsista CNPQ. Pesquisa a obra de Hans Bellmer e as ressonâncias do romantismo alemão sob orientação da Dra Karin Volobuef. Email: lucas.henrique-silva@unesp.br, ORCID: 0000-0001-5020-3138. Lattes: lattes.cnpq.br/0554596353026317
} 
índio e tintas como se vivesse uma vida prosaica de "menor articulada", expressão usada por Bellmer para definir o tema de seu ensaio.

Não seria na boneca que, apesar de sua doutrina acomodada e sem limites, cercouse de reserva desesperado e, na realidade mesma da boneca, a imaginação encontraria o que estava procurando de alegria, exaltação e medo? Seria isso o triunfo final das adolescentes [menor articulada] com olhos grandes que se transformam, se, sob o olhar consciente saqueando seus encantos, dedos agressivos assaltando a forma plástica e construindo lentamente, membro por membro, o que os sentidos e o cérebro tinham se apropriado (BELLMER, 2019, p. 39).

A Boneca trouxe Bellmer para a atenção do surrealismo e até hoje sua influência é notada na arte contemporânea. Podemos falar, por exemplo, da ressonância de Bellmer na arte de Louise Bourgeois. Os trabalhos Die Puppe/La Poupée/Les jeux de la Poupée - uma vez que a Boneca foi continuamente recriada em texto e imagem - marcaram o percurso da escultura surrealista, bem como da arte bruta. $\mathrm{Na}$ falta de entendimento de seu trabalho mesmo dentro do surrealismo, Bellmer escrevia enigmáticos "manuais de instrução". Pequenos textos sentimentais e, como diz o nome, ilustrativos do uso da Boneca. Esses textos permaneceram muitas vezes negligenciados, talvez pela suficiência visual da Boneca, o que dificultou a pesquisa desse artista. Em 2019, graças ao trabalho de Alexandre da Costa, estão disponíveis para leitura em português dez pequenos textos de Hans Bellmer. Muitos deles, vale destacar, ainda não tinham sequer tradução inglesa. Ainda que nos Estados Unidos a obra de Bellmer tenha sido exibida pelo acervo do Art Institute Chicago. Faltava - e ainda falta - tradução para este artista que também influenciou brasileiros como Tunga, por exemplo.

Bellmer viveu junto de Unica na rua Moufetard, onde o casal passava o tempo a produzir anagramas - jogos linguísticos baseados na inversão de letras em busca de uma nova palavra - e imagens repletas de erotismo e experimentalismo visual, em companhia da Boneca. Ele se dedicava cada vez mais às gravuras e desenhos, ela, escrevia histórias cada vez mais experimentais, sobre a vida de uma paciente psíquica. No desenho, Bellmer demonstrava um talento quase matemático - basta olhar para o traço de suas ilustrações. A simultaneidade impressa permitia que Bellmer trabalhasse mais rápido nas suas ideias sobre a reversibilidade da anatomia do que na escultura. Além da ilustração de trabalhos dentro do surrealismo, os títulos de Bellmer abrangem Marques de Sade (Petit traite de morale); o romantismo alemão (Les Marionettes), com o qual Bellmer remontava à tradição germânica; passava também por Georges Bataille (Madam Edwarda, Histoire de l'oeil). Bataille, o maior dissidente do surrealismo oficial - liderado por André Breton -, colaborou com Bellmer mais de uma vez. Sobre isso, o professor tradutor de Corpos labirínticos, Alexandre da Costa, pesquisa as ressonâncias filosóficas de Bataille em Bellmer. O texto "Entre labirintos e anagramas: o informo como dilaceramento dos corpos na obra de Hans Bellmer", publicado junto à edição (2019), serve como uma introdução aos dez textos traduzidos. Nele, somos apresentados a Bellmer sob a ótica do conceito de "informe", presente no vocabulário de Georges Bataille.

As identidades se tornam oscilantes, monstruosas, pois o que resta dos corpos repete gestos informes, ao serem levados a um estado crítico, a partir do qual a conjunção e a divergência estabelecem a descontinuidade como um processo de desestruturação da anatomia. Podemos analisar, dessa maneira, a fragmentação e o desdobramento, na obra de Hans Bellmer, à luz do informe, verbete formulado por Georges Bataille, para o dicionário crítico da revista Documents, em 1929, como um arranjo complexo de violentas forças irruptivas direcionadas à instabilidade (COSTA, 2019, p. 27).

Alexandre da Costa analisa, em outros textos de sua autoria disponíveis, a intertextualidade de Bellmer e o artista Nabuyoshi Araki, por exemplo, em artigo intitulado "Manifestações do informe" 
(2020: 11): "Se, em seu tratado de pintura, Leonardo da Vinci aconselha os pintores a buscarem imagens nas superfícies manchadas das paredes, Bellmer, ao utilizar a decalcomania em suas obras, parece seguir esse conselho à risca". Podemos pensar, também, na repercussão da obra $A$ Boneca no Japão, em obras populares no Ocidente como o jogo survival horror chamado Silent Hill (2001) e no longa de animação Ghost in the shell (2004). Nesse último, antes de conhecermos as "Ginóides", modelos robóticos femininos, é mostrado o livro de Hans Bellmer, Die Puppe. Em nota à tradução, Alexandre da Costa apura que os textos de Bellmer foram traduzidos para o japonês, além do italiano e do inglês. Esses fatos demonstram que a obra de Bellmer abre para uma série de possibilidades de pesquisa ainda pouco exploradas, principalmente no Brasil, onde se faz bastante dificultado o acesso a um artista como Bellmer, tanto pela problemática do idioma quanto pelo teor de sua obra.

Os textos são uma expressão importante do trabalho visual de Hans Bellmer. Isso porque a pedra de toque dos textos de Hans Bellmer é a visualidade da linguagem, que significa, também, a escrita do mundo visual. Para Bellmer, o corpo é como um anagrama. Alexandre da Costa analisa o jogo com o nonsense na obra de Bellmer como um dilaceramento da anatomia. Os experimentalismos ilimitados da Boneca estão pautados na tese de Bellmer de Petit anatomie de l'image, texto de 1957 em que Bellmer demonstra que, a partir de jogos de identificação, o Eu sodomiza o Outro assim como a frase sodomiza o verbo. Essas premissas, Bellmer exprimia não somente no texto traduzido na íntegra por Costa como "Pequena anatomia do inconsciente físico ou Pequena anatomia da imagem", mas também nos pequenos textos, muitas vezes publicado nos círculos surrealistas: "Mode d'emploi", "Striptease", são alguns destes textos agora disponíveis em português.

Por se tratar de um artista alemão com expressão francesa, a obra de Bellmer tanto movimenta uma barreira linguística quanto abre uma janela cultural para as relações entre França e Alemanha do século XX. Bellmer era um dos poucos artistas alemães em atividade no surrealismo no período da Segunda Guerra. Junto de Max Ernst, Bellmer foi tomado como prisioneiro na época da ocupação da França. Para retratar a sensação do cárcere, Bellmer retratou Max Ernst com o rosto simulando as paredes de tijolos. Essa experiência terrível o aproximou ainda mais da experiência de Sade. De alguma forma, Bellmer se sentia bastante grato aos seus amigos franceses que o ajudaram no exílio estado que Bellmer escolheu. Mesmo assim, ele não estava restrito ao círculo de Breton, como demonstra sua proximidade com Bataille, em quem acreditava, a ponto de destacar a relação com sua noção de Erotismo, divulgada por Bataille em sua obra, em ocasião de uma entrevista com o autor Peter Webb em Death, Desire and the Doll (2006). O estudo deste pesquisador inglês é crucial para entendermos a vida de Bellmer e as origens da Boneca na própria história da arte: "Bellmer iniciou sua nova vida como artista com a decisão de criar a Boneca" (WEBB, 2006, p. 3, tradução minha).

Sobre as particularidades da tradução de Bellmer, Alexandre da Costa especifica que Bellmer escrevia em alemão, para publicar francês por meio da colaboração com Robert Valançay. O título em alemão Kleine Anatomie des körperlich Unbewussten oder die Anatomie des Bildes, assim, torna-se Petit anatomie de l'image. Alexandre da Costa conta com o acervo bilíngue disponibilizado pela revista Obliques do texto de Hans Bellmer. Segundo ele, foram cotejados os textos em ordem de buscar uma melhor tradução dos termos de Bellmer. Para isso, contou-se também com publicações em inglês, no caso do texto principal de Bellmer, em duas edições da década passada. Esse cuidado na tradução é importante, pois, muitas vezes, Bellmer usa termos de origem quase polímata. Uma das principais referências de Bellmer é Girolamo Cardano, polímata do período do renascimento responsável pela divulgação das juntas esféricas. Bellmer aplica o conceito de Cardano na Boneca na década de 40, substituindo o material rígido pelas possibilidades visuais da esfera.

Acho que os diferentes modos de expressões: pose, gesto, ato, som, palavra, gráficos, criação de objetos, todos resultam do mesmo conjunto de mecanismos psicofisiológicos. Todos obedecem a uma mesma lei de nascimento. A expressão 
elementar, que não tem um propósito comunicativo pré-concebido, é um reflexo. A que necessidade, a que impulso o corpo obedece? Lembremo-nos dos reflexos causados por uma dor de dente, por exemplo, a contração violenta dos músculos da mão e dos dedos, cujas unhas afundam na pele (BELLMER, 2019, p. 67).

Além disso, outros termos da obra de Bellmer, como "inconsciente", por exemplo, chamam a atenção. Bellmer movimenta saberes da psicanálise, mas também da anatomia e da linguística, em torno da tese de que o corpo funciona como um anagrama. A ideia de um corpo virtual é relacionada com a existência de um inconsciente do corpo. Bellmer chama de "inconsciente físico". O termo "inconsciente" (Unbewussten) que compõe o título, de certa forma, autoriza a trajetória de Bellmer na psicanálise, área na qual seu trabalho recebeu diversas leituras importantes. Muitas destas abordagens, entretanto, insistem em aplicar a psicologia à obra de forma patologizante. Trata-se de uma tentativa de "traduzir" o choque de sua arte em termos de trauma ou processos psíquicos, como "sublimação", "passagem", "sintoma".

Apesar disso, não se pode retirar o mérito pesquisas fundamentais como a de Sue Taylor (2000): Anatomy of anxiety e Therese Lichtenstein (2001): Behind closed doors. Sue Taylor analisa o "fetichismo e a primeira boneca" (TAYLOR 2000: 12, tradução minha). Therese Lichtenstein (2001, p. 66, tradução minha) fala do "inquietante" que liga Bellmer a Freud. Existe um manancial muito rico de inquietações psicanalíticas na biografia de Bellmer, como podemos conferir no trabalho de Peter Webb de 2006. A vida de Bellmer resultou em uma formação artística invulgar - no sentido de formação tal como exprime o termo alemão Bildung. A arte de Bellmer está profundamente ligada com a sua biografia, mas de um modo que desafia o lugar do leitor receptor. Este, por sua vez, pode se valer de ferramentas diversas em busca de compreender tal objeto como A Boneca. A perspectiva filosófica do "informe", apresentada por Alexandre da Costa, vem a contribuir como um outro acesso ao pensamento de Hans Bellmer.

O leitor pode sentir falta das ilustrações, principalmente aquelas que acompanham o trabalho principal, "Pequena anatomia da imagem". Hans Bellmer é conhecido mais por seus desenhos do que seus textos, o que se deve muito ao "pensamento" que seus desenhos imprimem. Petit anatomie de l'image é um texto ilustrado, acompanha nove ou dez desenhos do próprio escritor, que transita de forma clara entre o visual e o verbal a fim de exprimir a sua ideia. No trabalho apresentado pela editora Gamma, não temos nenhuma dessas imagens provocantes de garotas com orifícios dimensionais, membros multiplicados ou interagindo anatomicamente com grãos de açúcar. As imagens que acompanham o texto são suprimidas, o que significa uma perda grave no apelo ao leitor. O texto, porém, apresenta uma visualidade na própria escrita. Nele já notamos o jogo com o textual e o visual, a simultaneidade das linguagens, dentre outras marcas do trabalho de Bellmer. Pode ser bastante difícil, em uma publicação reduzida, divulgar estas imagens junto do texto. A edição peca por não indicar a presença dessas imagens para o leitor desavisado. Fica no horizonte a expectativa de um trabalho de peso - literalmente - que contenha os trabalhos de Bellmer reunidos e "completos", isso é, texto e imagem respectiva, com o trabalho à altura de um escritor que tinha paixão pelo design e pela experiência do objeto livro - conta-se que nas primeiras edições de Les jeux de la Poupée, exalava do material um perfume doce, em função de recriar material e sensorialmente a experiência da Boneca.

Ao comparar com uma edição mais completa de "Pequena anatomia da imagem", como a da Dominion Press (EUA, 2004), traduzida do francês por Jon Graham para o inglês, "Little anatamy of the unconscious, or the Anatomy of the image", nota-se a diferença - de investimento - que a ilustração acrescenta ao texto. O tradutor Jon Graham, da edição inglesa de Petit anatomie, fala sobre a obscuridade que permanece sobre esse texto de Bellmer (2004). Além desse, também faltam as imagens do trabalho Mode d'Emploi, que originalmente continha imagens. Esse texto foi publicado 
somente em 1967, pela companhia de Georges Visat e continha 4 gravuras feitas especialmente para ilustrar as proposições da tese de Bellmer de que as juntas esféricas ilustram também o desenvolvimento da anatomia e sua reversibilidade. Trata-se de um texto para ser lido junto de Petit anatomie, mas também das imagens de Bellmer. Visualmente, no Brasil, Bellmer segue restrito à escultura e a fotografia, por meio do interesse recorrente pela Boneca. Porém, para Bellmer, imagem muitas vezes equivale a "texto". Para ele, a imagem é tomada pelo estatuto de uma escrita, o que faz da letra uma ferramenta de visualidade, que compreende também a imagem das imagens: o corpo e sua anatomia.

\section{Referências bibliográficas}

BELlMER, H. A Boneca. In: COSTA, A. R. (Org.). Corpos labirínticos: textos de Hans Bellmer. Tradução de Alexandre Rodrigues da Costa. Rio de Janeiro: Gramma, 2019, 41-45.

BELlMER, H. Pequena anatomia do inconsciente físico ou Pequena anatomia da imagem. In: COSTA, A. R. (Org.). Corpos labirínticos: textos de Hans Bellmer. Tradução de Alexandre Rodrigues da Costa. Rio de Janeiro: Gramma, 2019, 67-107.

COSTA, A. R. Manifestações do informe: a nuvem e a mancha como disruptura do visível nas obras de Hans Bellmer e Nobuyoshi Araki. Visualidades, 18, 24, 2020.

COSTA, A. R. Entre labirintos e anagramas: o informe como dilaceramento dos corpos na obra de Hans Bellmer. In: COSTA, A. R. (Org.). Corpos labirínticos: textos de Hans Bellmer. Tradução de Alexandre Rodrigues da Costa. Rio de Janeiro: Gramma, 2019, 1-33.

LICHTENSTEIN, T. Behind closed doors: the art of Hans Bellmer. California: International Center of Photography, 2001.

TAYLOR, S. Hans Bellmer: the anatomy of anxiety. Massachusetts: MIT, 2000.

WEBB, P. Death, Desire \& the Doll: the life and art of Hans Bellmer. USA: Solar Books, 2006. 